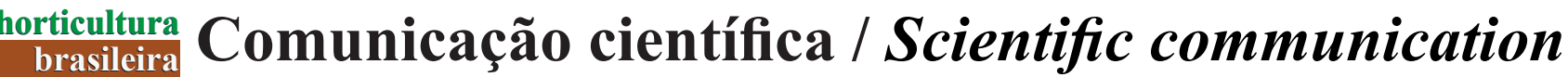

SILVA GC; OLIVEIRA LM; LUCCHESE AM; SILVA TRS; NASCIMENTO MN. 2015. Propagação vegetativa e crescimento inicial de Lippia origanoides (alecrim-de-tabuleiro). Horticultura Brasileira 33: 236-240. DOI - http://dx.doi.org/10.1590/S0102-053620150000200016

\section{Propagação vegetativa e crescimento inicial de Lippia origanoides (alecrim-de-tabuleiro)}

\author{
Gabriela C Silva $^{1}$; Lenaldo M Oliveira ${ }^{1}$; Angélica M Lucchese ${ }^{2}$; Tânia RS Silva ${ }^{1}$; Marilza N Nascimento ${ }^{1}$ \\ ${ }^{1}$ UEFS, Depto. Ciências Biológicas, Av. Transnordestina, s/n, Novo Horizonte, 44036-900 Feira de Santana-BA; gabicarinhanha@ \\ gmail.com; lenaldo.uefs@gamil.com; tanialantana@gmail.com; marilzaagro@hotmail.com²UEFS, Depto. Ciências Exatas; angelica. \\ lucchese@gmail.com
}

\section{RESUMO}

Alecrim-de-tabuleiro (Lippia origanoides) é arbusto aromático medicinal promissor, porém com poucos estudos sobre propagação e cultivo. Este trabalho objetivou avaliar a influência de diferentes substratos e concentrações de ácido indolbutírico (AIB) na propagação de alecrim-de-tabuleiro por estacas apicais. As concentrações testadas foram $0 ; 62,5 ; 125 ; 250$ e $500 \mathrm{mg} / \mathrm{L}$ e os substratos utilizados consistiram em Biomix ${ }^{\circledR}$ (substrato comercial), vermiculita expandida e a mistura de Biomix + vermiculita expandida (1:1). O delineamento experimental utilizado foi inteiramente casualizado em parcelas subdivididas, tendo substratos como parcelas e concentrações de AIB como subparcelas. $\mathrm{O}$ enraizamento das estacas ocorreu independentemente da aplicação exógena de AIB e do tipo de substrato. A mistura de Biomix e vermiculita expandida (1:1) promoveu maior produção de folhas, raízes e de massa seca. A aplicação de pequenas doses de AIB melhorou o crescimento das mudas. É possível a produção de mudas de alecrim-de-tabuleiro por estaquia a partir de segmentos apicais. O cultivo em substrato constituído por mistura de Biomix e vermiculita expandida (1:1) proporciona maior desenvolvimento radicular e melhor crescimento inicial das brotações, sendo o substrato mais recomendável para a propagação dessa espécie.

\begin{abstract}
Vegetative propagation and early growth of Lippia origanoides (alecrim-de-tabuleiro)

Lippia origanoides (alecrim-de-tabuleiro) is a promising medicinal aromatic shrub, no studies are available about propagation and cultivation. This work aimed to evaluate the influence of different substrates and indolbutiric acid (IBA) levels on the propagation of apical cuttings of this species. Five IBA levels $(0 ; 62.5 ; 125 ; 250$ and $500 \mathrm{mg} / \mathrm{L}$ ) and three substrates were evaluated: Biomix ${ }^{\circledR}$ (commercial substrate); expanded vermiculite and Biomix + expanded vermiculite (1:1). Experimental design was completely randomized in split plots, with substrates as plots and IBA levels as subplots. Rooting occurred independently of the exogenous application of IBA and the type of substrate. The Biomix and expanded vermiculite (1:1) mix showed higher production of leaves, roots and dry weight. The application of small doses of IBA improved growth of seedlings. It is possible to produce alecrim-de-tabuleiro seedlings using apical cuttings. Apical cutting cultivation on Biomix and expanded vermiculite $(1: 1)$ mix promoted better root development and early shoots growth and was the most recommended substrate for the propagation of this species.
\end{abstract}

Palavras-chave: Verbenaceae, estaquia, planta medicinal e aromática.

Keywords: Verbenaceae, cutting, medicinal and aromatic plant.

(Recebido para publicação em 29 de novembro de 2013; aceito em 5 de janeiro de 2015) (Received on November 29, 2013; accepted on January 5, 2015)

\begin{abstract}
Tippia origanoides (alecrim-detabuleiro, Verbenaceae) é nativa do semiárido brasileiro (Govaerts \& Atkins, 2012; Salimena, 2012). Na medicina popular é utilizada na forma de decocto ou macerado em álcool no tratamento de problemas gastrointestinais, infecções microbianas e doenças das vias respiratórias, incluindo asma, bronquite, gripe, resfriado e tosse (Pascual et al., 2001; Agra et al., 2007). O uso medicinal da espécie tem sido atribuído ao seu óleo essencial, encontrado principalmente em folhas e inflorescências, com atividade contra espécies de Candida, Cryptococcus
\end{abstract}

neoformans, Trichophytum rubrum, Fonsecaea pedrosoi, Staphylococcus aureus, Lactobacillus casei, Streptococcus mutans (Oliveira et al., 2007), Trypanosoma cruzi e Leishmania chagasi (Escobar et al., 2010). O extrato etanólico do alecrim-de-tabuleiro apresenta ainda ação anticolinesterásica, sequestradora de radicais livres (Morais et al., 2008) e ação citotóxica contra linhagens de células cancerígenas (Santos et al., 2003).

Apesar do grande potencial farmacológico e econômico do alecrim-de-tabuleiro, sua exploração tem sido realizada de forma extrativista e artesanal, como ocorre com a maioria das espécies medicinais nativas do Brasil (Ming et al., 2003). Pesquisas devem ser intensificadas buscando gerar informações sobre a fisiologia, propagação e cultivo dessa espécie, as quais poderão contribuir com a criação da cadeia produtiva e consequente utilização pela indústria farmacêutica. Contudo, a propagação de plantas medicinais nativas via sementes tem se mostrado inadequada para a maioria das espécies, tendo em vista a grande variabilidade genética (França, 2002), o tempo necessário para se alcançar a fase adulta e problemas relacionados à 
viabilidade e à dormência das sementes (Wendling, 2004). As sementes do alecrim-de-tabuleiro possuem ainda difícil visualização e manuseio, devido ao seu tamanho reduzido (Herrera-Moreno et al., 2013). Por outro lado, a reprodução vegetativa tem sido considerada alternativa promissora para produção de mudas de plantas medicinais, possibilitando qualidade genética, baixo custo, tempo reduzido, sendo a estaquia o método mais difundido.

A produção de mudas por estaquia é influenciada por vários fatores, como o tipo e a época de colheita das estacas, o tipo de substrato utilizado e o balanço adequado entre fito-hormônios ou reguladores necessários à indução do enraizamento (Oliveira et al., 2003). A utilização de reguladores de crescimento vegetais tem se revelado procedimento eficiente para o sucesso da estaquia em muitas espécies, embora as respostas sejam muito dependentes da espécie, genótipo, idade da planta e tipo de estaca (Wendling, 2004), sendo as auxinas a classe mais difundida para esse fim. $\mathrm{Na}$ estaquia de variedades de pessegueiros (Prunus persica), a aplicação de AIB promoveu aumento na porcentagem de enraizamento, no número de raízes por estaca e na massa seca das raízes, elevando de $0 \%$ para $91,34 \%$ de estacas enraizadas quando coletadas no verão (Dutra et al., 2002).

Quanto ao tipo de substrato, suas características físicas e químicas influenciam diretamente a sobrevivência e o enraizamento das estacas. Em geral, o substrato ideal para a estaquia deve, além de servir de suporte mecânico para a fixação das estacas, disponibilizar os nutrientes necessários ao desenvolvimento vegetativo inicial e apresentar alto grau de porosidade, facilitando o crescimento radicular (Lacerda et al., 2006).

Para o alecrim-de-tabuleiro, estudos sobre estaquia são escassos. Herrera-Moreno et al. (2013) avaliaram um método de propagação vegetativa com a utilização de substratos alternativos \{fibra de coco; fibra de coco + escória de carvão (1:1) e fibra de coco + escória de carvão + areia $(1: 1: 1)\}$ e diferentes concentrações de AIB (0; 2000 e 4000 $\mathrm{mg} / \mathrm{L})$ e verificaram que a maior percentagem de enraizamento das estacas ocorreu com a utilização do substrato constituído de fibra de coco na ausência do regulador; entretanto, verificaram baixo desempenho das plantas obtidas, sugerindo novos estudos com metodologias diferentes e menores concentrações de auxina.

Neste trabalho objetivou-se estudar a influência do ácido indolbutírico e substratos na produção e no crescimento inicial de mudas via estacas apicais de alecrim-de-tabuleiro.

\section{MATERIAL E MÉTODOS}

O experimento foi conduzido na Unidade Experimental Horto Florestal da Universidade Estadual de Feira de Santana (UEFS), Feira de Santana-BA, (12¹6'00"S, 38 58'00"O, 257 metros de altitude). A precipitação média anual é de $848 \mathrm{~mm}$ e a temperatura média de $24^{\circ} \mathrm{C}$.

Os tratamentos testados foram concentrações de AIB de $0 ; 62,5 ; 125$; 250 e $500 \mathrm{mg} / \mathrm{L}$ combinadas com os substratos Biomix (S1), vermiculita expandida (S2) e a mistura de Biomix e vermiculita expandida na proporção de 1:1 (S3). O delineamento foi inteiramente casualizado, em esquema de parcelas subdivididas no espaço, no qual o fator de variação substrato constituiu a parcela e a concentração de AIB, as subparcelas. Cada subparcela constou de três repetições, cada uma contendo doze estacas, totalizando 180 indivíduos por parcela.

Biomix é um substrato comercial utilizado na produção de mudas de hortaliças, constituído por casca de pinus compostada, vermiculita expandida e composto orgânico, apresentando $\mathrm{pH}$ 6,2 , capacidade de retenção de água de $50 \%$ e densidade na base seca de $350 \mathrm{~kg} /$ $\mathrm{m}^{3}$. A vermiculita expandida utilizada apresentou granulometria fina composta, segundo informação do fabricante, por 34 a $43 \%$ de óxido de silício $\left(\mathrm{SiO}_{2}\right)$; 7 a $15 \%$ de óxido de alumínio $\left(\mathrm{Al}_{2} \mathrm{O}_{3}\right)$; 5 a $13 \%$ de óxido férrico $\left(\mathrm{Fe}_{2} \mathrm{O}_{3}\right) ; 20$ a $28 \%$ de óxido de magnésio $(\mathrm{MgO})$; 0,01 a $0,1 \%$ de óxido de potássio $\left(\mathrm{K}_{2} \mathrm{O}\right)$; 0,2 a $1 \%$ de óxido de cálcio $(\mathrm{CaO}) ; 0,1$ a $0,3 \%$ de óxido de sódio $\left(\mathrm{Na}_{2} \mathrm{O}\right)$ e 6 a $12 \%$ de água; $\mathrm{pH}$ entre 6 e 8 ; capaci-

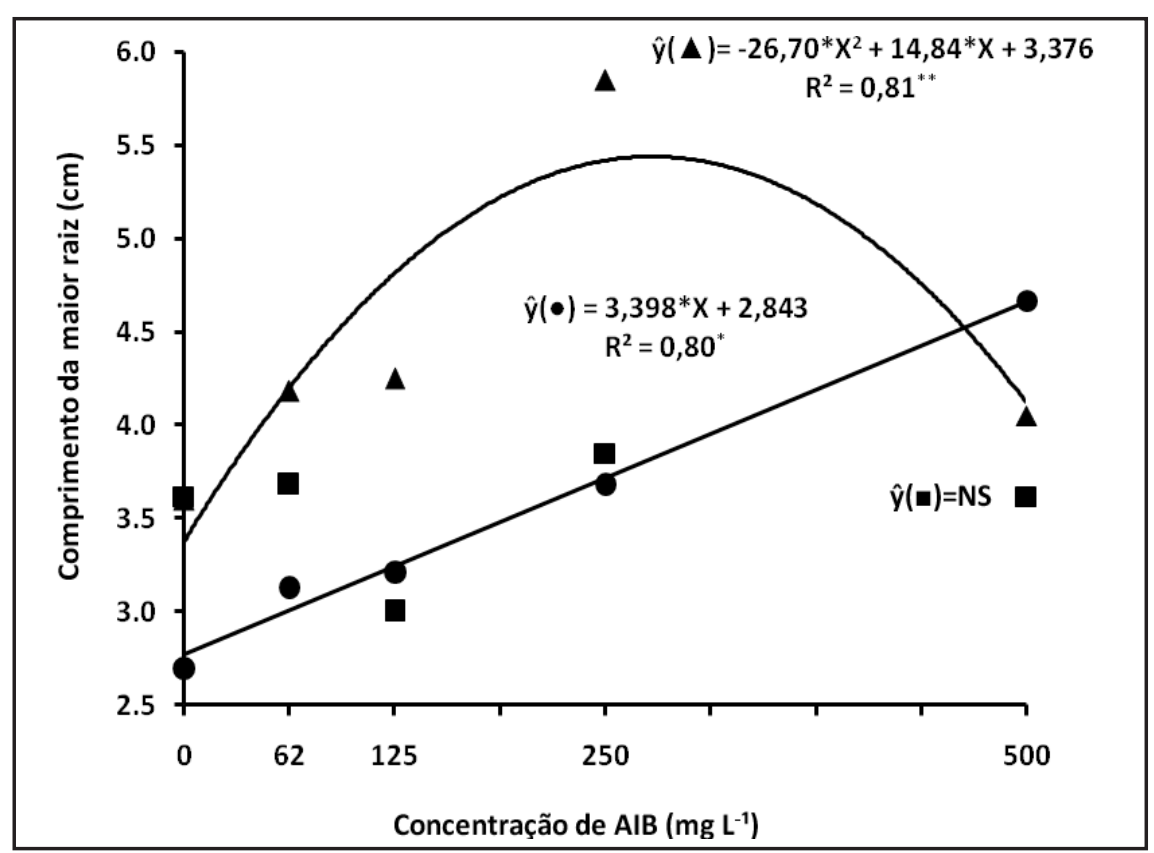

Figura 1. Comprimento da maior raiz de estacas do alecrim-de-tabuleiro cultivadas nos

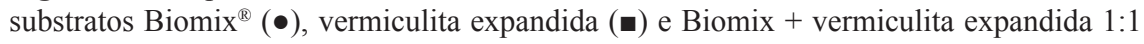
$(\boldsymbol{\Delta})$ e tratadas com cinco concentrações de ácido indolbutírico (AIB); ${ }^{*} \mathrm{e}^{* *}$ significativos a $1 \%$ e $5 \%$ de probabilidade pelo teste de F, respectivamente; ${ }^{N S}$ não significativo pelo teste de $\mathrm{F}$ \{length of the largest root of cuttings of Lippia origanoides grown on substrates Biomix ${ }^{\circledR}$ $(\bullet)$, expanded vermiculite $(\boldsymbol{\bullet})$ and Biomix + expanded vermiculite 1:1 ( $\mathbf{\Delta})$ and treated with five concentrations of indolbutiric acid (IBA); ${ }^{*}$ and ${ }^{* *}$ means significant at $1 \%$ and $5 \%$ by the F test, respectively, ${ }^{\mathrm{NS}}$ not significant by the F test $\}$. Feira de Santana, UEFS, 2012. 
dade de retenção de água de até $600 \%$ do peso; densidade de 60 a $160 \mathrm{~kg} / \mathrm{m}^{3}$.

Estacas apicais do alecrim-de-tabuleiro foram obtidas a partir de plantas matrizes na coleção de plantas aromáticas da UEFS, cuja exsicata foi identificada e encontra-se depositada no herbário da mesma instituição (HUEFS 83.373). Estacas com $10 \mathrm{~cm}$ e contendo de três a cinco folhas tiveram dois centímetros de suas bases imersas em solução de AIB nas respectivas concentrações, por 24 horas. Depois, foram plantadas em bandejas de poliestireno (isopor) contendo 200 poços, preenchidos com os diferentes substratos. As bandejas foram mantidas em casa de vegetação com cobertura plástica transparente, com $75 \%$ de passagem de luz e nebulização intermitente, com intervalos de 30 minutos entre nebulizações de três minutos, controlado por temporizador digital.

Após 45 dias de cultivo foram avaliadas as porcentagens de enraizamento e de sobrevivência das estacas; comprimento do caule (compreendendo desde a base até o ramo mais alto) e da maior raiz; número de folhas por muda; massa seca de raiz, caule, folhas e total. Os resultados obtidos foram submetidos inicialmente à análise de variância pelo teste $\mathrm{F}$ e, posteriormente, ao teste de Tukey para o tipo de substrato e à análise de regressão e Scott-Knott para as concentrações de AIB, ambos a 5\% de probabilidade de erro. As análises estatísticas foram realizadas usando o programa Sisvar 5.3.

\section{RESULTADOS E DISCUSSÃO}

Verificou-se interação significativa

Tabela 1. Taxa de sobrevivência, número de folhas e comprimento do caule de mudas de alecrim-de-tabuleiro propagadas a partir de estacas apicais cultivadas em diferentes substratos e concentrações de ácido indolbutírico (survival rate, number of leaves per seedling and stem length of Lippia origanoides propagated from apical cuttings cultivated in different substrates and levels of indolbutiric acid). Feira de Santana, UEFS, 2012.

\begin{tabular}{|c|c|c|c|c|c|c|}
\hline \multirow{2}{*}{ Substrato } & \multicolumn{5}{|c|}{ Concentração de AIB (mg/L) } & \multirow{2}{*}{ Média } \\
\hline & 0 & 62,5 & 125 & 250 & 500 & \\
\hline \multicolumn{7}{|c|}{ Sobrevivência (\%) } \\
\hline $\mathrm{S} 1$ & $38,8 \mathrm{cD}$ & $88,8 \mathrm{aA}$ & $76,6 \mathrm{aB}$ & $68,8 \mathrm{aC}$ & $76,2 \mathrm{aB}$ & 69,8 \\
\hline S2 & $48,8 \mathrm{bC}$ & $55,0 \mathrm{cC}$ & $73,8 \mathrm{aA}$ & $50,0 \mathrm{bC}$ & $62,5 \mathrm{bB}$ & 58,0 \\
\hline $\mathrm{S} 3$ & $67,5 \mathrm{aA}$ & $73,8 \mathrm{bA}$ & $61,3 \mathrm{bB}$ & $42,5 \mathrm{bC}$ & $71,3 \mathrm{aA}$ & 63,3 \\
\hline Média & 51,7 & 72,5 & 70,6 & 53,7 & 70,0 & \\
\hline CV $(\%)$ & 11,56 & & & & & \\
\hline \multicolumn{7}{|c|}{ Número de folhas/planta } \\
\hline $\mathrm{S} 1$ & $3,7 \mathrm{cB}$ & $2,5 \mathrm{cB}$ & $9,7 \mathrm{bA}$ & $8,7 \mathrm{bA}$ & $1,3 \mathrm{cB}$ & 5,2 \\
\hline S2 & $13,7 \mathrm{bA}$ & $10,2 b B$ & $13,3 \mathrm{bA}$ & $15,0 \mathrm{aA}$ & $11,3 \mathrm{bB}$ & 11,6 \\
\hline S3 & $19,2 \mathrm{aB}$ & $17,0 \mathrm{aC}$ & $25,7 \mathrm{aA}$ & $9,7 \mathrm{bC}$ & $18,7 \mathrm{aB}$ & 19,1 \\
\hline$\overline{\text { Média }}$ & 12,2 & 9,9 & 16,2 & 11,1 & 10,4 & \\
\hline CV $(\%)$ & 27,11 & & & & & \\
\hline \multicolumn{7}{|c|}{ Comprimento do caule $(\mathrm{cm})$} \\
\hline$\overline{\mathrm{S} 1}$ & $11,57 \mathrm{abA}$ & $10,42 \mathrm{bB}$ & $12,07 \mathrm{aA}$ & $11,42 \mathrm{abA}$ & $12,25 \mathrm{aA}$ & 11,56 \\
\hline S2 & $10,78 \mathrm{bB}$ & $11,22 \mathrm{bB}$ & $11,58 \mathrm{aA}$ & $12,38 \mathrm{aA}$ & $10,57 \mathrm{bB}$ & 11,02 \\
\hline S3 & $12,28 \mathrm{aB}$ & $14,42 \mathrm{aA}$ & $12,57 \mathrm{aB}$ & $10,95 \mathrm{bC}$ & $12,75 \mathrm{aB}$ & 12,88 \\
\hline$\overline{\text { Média }}$ & 11,54 & 12,02 & 12,07 & 11,58 & 11,86 & \\
\hline CV (\%) & 6,46 & & & & & \\
\hline
\end{tabular}

$\mathrm{S} 1=$ Biomix $^{\circledR} ; \mathrm{S} 2=$ vermiculita expandida; $\mathrm{S} 3=$ Biomix + vermiculita $1: 1 ; \mathrm{AIB}=$ ácido indolbutírico; médias seguidas pela mesma letra minúscula nas colunas e maiúscula nas linhas não diferem a $5 \%$ de probabilidade, pelos testes de Tukey e Scott-Knott, respectivamente $\left(\mathrm{S} 1=\right.$ Biomix $^{\circledR} ; \mathrm{S} 2=$ expanded vermiculite; $\mathrm{S} 3=$ Biomix + vermiculite $1: 1 ; \mathrm{AIB}=$ indolbutiric acid; means followed by the same lowercase letter in the columns and uppercase letter in the lines are not significantly different at $5 \%$ by Tukey and Scott-Knott test, respectively).

entre os tipos de substrato e as concentrações de AIB para as características avaliadas, com exceção da porcentagem de enraizamento. Ocorreu $100 \%$ de enraizamento nas estacas, demonstrando alta capacidade de emissão de raízes das estacas apicais do alecrim-de-tabuleiro, diferentemente dos resultados observados com estacas medianas de duas variedades desta espécie (Herrera-Moreno et al., 2013). A produção endógena de auxina, possivelmente, foi suficiente para a promoção da rizogênese nessas estacas, sem a necessidade do uso de biorreguladores vegetais. O ácido indol-3-acético (AIA), uma auxina natural, é produzido por células do meristema apical do caule e transportado por vias específicas como sinal químico a fim de regular a diferenciação celular e a formação de raízes laterais e adventícias (Aloni et al., 2006).

Outros trabalhos realizados com espécies de Lippia também têm demonstrado a facilidade de emissão de raízes em estacas apicais, como verificado para Lippia gracilis que apresentou 100\% das estacas enraizadas independentemente do substrato testado (Oliveira et al., 2011) e Lippia alba que enraizou com a utilização de diferentes tipos de substratos e independente da utilização de auxinas (Biasi \& Costa, 2003). Por outro lado, Pimenta et al. (2007) demonstraram que para as espécies Lippia glandulosa, Lippia rotundifolia, Lippia filifolia e Lippia rosella a propagação por estaquia mostrou-se pouco eficaz, devido à reduzida ou ausente emissão de raízes, mesmo com a utilização de biorreguladores.

Estacas apicais cultivadas em substrato constituído da mistura de Biomix e vermiculita, utilizando-se a concentração estimada de $278 \mathrm{mg} / \mathrm{L}$ de AIB, apresentaram o maior comprimento de raiz $(5,4 \mathrm{~cm})$ (Figura 1$)$. Com base nestes resultados, supõe-se que auxina exógena favorece o desenvolvimento das raízes das mudas. Em estacas de oliveira (Olea europaea), o aumento da concentração de AIB promoveu elevação na porcentagem de enraizamento, no comprimento da raiz e no número de raízes, quando produzidas em determinados períodos do ano (Oliveira et al., 2003). Porém, Herrera-Moreno et 
Tabela 2. Massa seca de folhas, caule, raiz e total de mudas de alecrim-de-tabuleiro propagadas a partir de estacas apicais, cultivadas em diferentes substratos e concentrações de ácido indolbutírico (average dry mass of leaves, stem, root and total seedlings of Lippia origanoides propagated from apical cuttings, grown in different substrates and levels of indolbutiric acid). Feira de Santana, UEFS, 2012.

\begin{tabular}{|c|c|c|c|c|c|c|}
\hline \multirow{2}{*}{ Substrato } & \multicolumn{5}{|c|}{ Concentração de AIB (mg/L) } & \multirow{2}{*}{ Média } \\
\hline & 0 & 62,5 & 125 & 250 & 500 & \\
\hline \multicolumn{7}{|c|}{ Massa seca de folhas (mg/planta) } \\
\hline $\mathrm{S} 1$ & $9,6 \mathrm{cB}$ & $6,5 \mathrm{bB}$ & $25,7 \mathrm{bA}$ & $14,8 \mathrm{bA}$ & $1,3 \mathrm{cB}$ & 11,6 \\
\hline S2 & $28,6 \mathrm{bA}$ & $42,7 \mathrm{aA}$ & $28,5 \mathrm{bA}$ & $34,2 \mathrm{aA}$ & $23,5 \mathrm{bA}$ & 31,5 \\
\hline $\mathrm{S} 3$ & $53,2 \mathrm{aA}$ & $49,5 \mathrm{aA}$ & $53,2 \mathrm{aA}$ & 25,2abB & $58,2 \mathrm{aA}$ & 48,2 \\
\hline Média & 30,5 & 32,9 & 35,8 & 24,7 & 27,7 & \\
\hline CV $(\%)$ & 42,20 & & & & & \\
\hline \multicolumn{7}{|c|}{ Massa seca do caule (mg/planta) } \\
\hline $\mathrm{S} 1$ & $61,3 \mathrm{aB}$ & $52,8 \mathrm{bB}$ & $77,0 \mathrm{aA}$ & $76,5 \mathrm{aA}$ & $56,3 \mathrm{abB}$ & 64,8 \\
\hline S2 & $74,0 \mathrm{aA}$ & $53,7 \mathrm{bB}$ & $71,2 \mathrm{aA}$ & $80,2 \mathrm{aA}$ & $43,0 \mathrm{bB}$ & 64,4 \\
\hline $\mathrm{S} 3$ & $71,2 \mathrm{aA}$ & $83,5 \mathrm{aA}$ & $79,3 \mathrm{aA}$ & $51,7 \mathrm{bB}$ & $63,5 \mathrm{aB}$ & 69,8 \\
\hline Média & 68,8 & 63,3 & 75,8 & 69,5 & 54,3 & \\
\hline $\mathrm{CV}(\%)$ & 23,83 & & & & & \\
\hline \multicolumn{7}{|c|}{ Massa seca da raiz (mg/planta) } \\
\hline $\mathrm{S} 1$ & $8,8 \mathrm{bC}$ & $17,3 \mathrm{bB}$ & $32,2 \mathrm{bA}$ & $20,8 \mathrm{aB}$ & $30,8 \mathrm{bA}$ & 22,0 \\
\hline S2 & $15,7 \mathrm{bB}$ & $10,0 \mathrm{bB}$ & $12,2 \mathrm{cB}$ & $25,5 \mathrm{aA}$ & $11,8 \mathrm{cB}$ & 13,6 \\
\hline $\mathrm{S} 3$ & $30,2 \mathrm{aB}$ & $29,7 \mathrm{aB}$ & $43,0 \mathrm{aA}$ & $18,2 \mathrm{aC}$ & $48,0 \mathrm{aA}$ & 35,28 \\
\hline Média & 18,2 & 19,0 & 29,1 & 21,5 & 30,2 & \\
\hline $\mathrm{CV}(\%)$ & 29,15 & & & & & \\
\hline \multicolumn{7}{|c|}{ Massa seca total (mg/planta) } \\
\hline $\mathrm{S} 1$ & $123,9 \mathrm{bB}$ & $122,7 \mathrm{bB}$ & $212,1 \mathrm{bA}$ & $169,9 \mathrm{bA}$ & $136,9 \mathrm{bB}$ & 153,4 \\
\hline $\mathrm{S} 2$ & $181,3 \mathrm{abA}$ & $167,0 \mathrm{bA}$ & $169,1 \mathrm{bA}$ & $217,8 \mathrm{aA}$ & $138,8 \mathrm{bA}$ & 174,4 \\
\hline $\mathrm{S} 3$ & $238,8 \mathrm{aA}$ & $254,7 \mathrm{aA}$ & $282,7 \mathrm{aA}$ & $153,0 \mathrm{bB}$ & $259,8 \mathrm{aA}$ & 237,8 \\
\hline Média & 181,3 & 181,4 & 221,3 & 180,2 & 178,4 & \\
\hline $\mathrm{CV}(\%)$ & 32,18 & & & & & \\
\hline
\end{tabular}

$\mathrm{S} 1=$ Biomix $^{\circledR} ; \mathrm{S} 2=$ vermiculita expandida; $\mathrm{S} 3=$ Biomix + vermiculita 1:1; $\mathrm{AIB}=$ ácido indolbutírico; médias seguidas pela mesma letra minúscula nas colunas e maiúscula nas linhas não diferem a $5 \%$ de probabilidade, pelos testes de Tukey e Scott-Knott, respectivamente $\left(\mathrm{S} 1=\right.$ Biomix $^{\circledR} ; \mathrm{S} 2=$ expanded vermiculite; $\mathrm{S} 3=$ Biomix + vermiculite $1: 1 ; \mathrm{AIB}=$ indolbutiric acid; Means followed by the same lowercase letter in the columns and uppercase letter in the lines are not significantly diferent at $5 \%$ by Tukey and Scott-Knott test, respectively).

al. (2013), em experimento realizado com duas variedades colombianas de alecrim-de-tabuleiro, obtiveram maior comprimento de raízes em estacas sem o uso da auxina.

A maior taxa de sobrevivência foi observada quando as estacas foram tratadas com solução de AIB de 62,5 $\mathrm{mg} / \mathrm{L}$ e cultivadas em Biomix. O maior comprimento do caule foi alcançado com a utilização de $62,5 \mathrm{mg} / \mathrm{L}$ de $\mathrm{AIB}$ e a mistura de Biomix e vermiculita expandida na proporção de 1:1. Maior número de folhas e massa seca da raiz foram o que explica as diferentes respostas obtidas com as espécies de Lippia. Em Lippia sidoides por exemplo, Oliveira et al. (2008) verificaram que a imersão de estacas apicais durante 20 horas em solução de $250 \mathrm{mg} / \mathrm{L}$ de AIB promoveu aumento de cerca de $270 \%$ no número de raízes por estaca e de $350 \%$ nas estacas enraizadas. Por outro lado, Figueiredo et al. (2009), trabalhando com essa mesma espécie, não detectaram influência da aplicação exógena de AIB sobre o enraizamento de estacas medianas. Com alecrim-de-tabuleiro, Herrera-Moreno et al. (2013) não obtiveram efeito positivo do uso de 2000 ou $4000 \mathrm{mg} / \mathrm{L}$ de AIB sobre a massa seca das raízes de estacas medianas.

Apesar do substrato comercial Biomix ter promovido maiores taxas de sobrevivência das estacas, a mistura Biomix + vermiculita expandida (1:1) possibilitou maior crescimento inicial das mudas, o que pode ser atribuído à maior capacidade de adsorção de nutrientes aliada à maior capacidade de retenção de água da mistura, resultante da adição da vermiculita. Fochesato et al. (2008) ressaltam que a disponibilidade de nutrientes minerais no substrato depende do consumo pela planta, da lixiviação e da adsorção ao substrato, o que está relacionado às suas características químicas e físicas. Com L. alba, por exemplo, Biasi \& Costa (2003) verificaram maior comprimento do broto em estacas cultivadas em substrato comercial Plantmax (casca de pinus, turfa, vermiculita expandida e carvão moído) em comparação com vermiculita, sendo este resultado atribuído ao baixo teor de nutrientes no substrato inorgânico. Para as variedades de alecrim-de-tabuleiro CA-90 e CA-93, os substratos compostos por fibra de coco e fibra de coco + escória de carvão + areia (1:1:1) promoveram maior crescimento da raiz quando comparados à mistura de fibra de coco + escória de carvão (1:1) (Herrera-Moreno et al., 2013).

Os resultados obtidos com o uso da mistura Biomix + vermiculita expandida $(1: 1)$ podem ser devidos às suas características físicas e químicas: elevado teor dos macro e micronutrientes do Biomix e grande capacidade de adsorção e retenção de água e elevada porosidade 
da vermiculita expandida. Esses fatores possivelmente criaram condições mais favoráveis ao desenvolvimento das raízes e, consequentemente, crescimento da parte aérea. Contudo, o tipo de substrato mais adequado varia em função da espécie estudada: na estaquia de L. sidoides o substrato mais aerado e com menos nutrientes (areia) promoveu maior acúmulo de massa fresca, maior número de folhas expandidas e maior número de brotos por estaca (Oliveira et al., 2008); em estacas de atroveram (Ocimum selloi) não se verificou influência de substratos com diferentes características físico-químicas no desenvolvimento radicular das mesmas (Costa et al., 2007); já na propagação da espécie medicinal alfavaca-cravo (Ocimum gratissimum), a utilização de substrato composto por $40 \%$ de areia fina mais esterco bovino ou $40 \%$ de húmus mais vermiculita promoveu maior desenvolvimento, tanto da parte aérea quanto das raízes (Ehlert et al., 2004).

A aplicação de pequenas doses de AIB aumenta o crescimento das mudas, contudo, o substrato Biomix + vermiculita (1:1) foi o principal promotor do aumento de biomassa nessa espécie, com destaque ao crescimento do tecido fotossintetizante. Ressalta-se que no cultivo, além do enraizamento e sobrevivência das estacas, é desejável a obtenção de mudas com bom desenvolvimento, tanto do sistema radicular quanto da parte aérea, para a garantia de alta taxa de sobrevivência após o transplante e rápido estabelecimento no campo.

Conclui-se que é possível a produção de mudas de alecrim-de-tabuleiro por estaquia a partir de segmentos apicais. O cultivo em substrato constituído da mistura de Biomix + vermiculita (1:1) proporciona maior desenvolvimento radicular e melhor crescimento inicial das mudas, sendo o método mais recomendável para a propagação dessa espécie.

\section{AGRADECIMENTOS}

À Coordenação de Aperfeiçoamento de Pessoal de Nível Superior (CAPES), pela concessão de bolsas e à Fundação de Amparo à Pesquisa do Estado de Bahia (FAPESB) e ao Conselho Nacional de Desenvolvimento Científico e
Tecnológico (CNPq), pelo apoio financeiro à realização do projeto.

\section{REFERÊNCIAS}

AGRA MF; FREITAS PF; BARBOSA-FILHO JM. 2007. Synopsis of the plants known as medicinal and poisonous in Northeast of Brazil. Revista Brasileira de Farmacognosia 17: 14-140.

ALONI R; ALONI E; LANGHANS M; ULLRICH CI. 2006. Role of cytokinin and auxin in shaping root architecture: regulating vascular differentiation, lateral root initiation, root apical dominance and root gravitropism. Annals of Botany 97: 883-893.

BIASI LA; COSTA G. 2003. Propagação vegetativa de Lippia alba. Ciência Rural 33: 455-459.

COSTA LCB; PINTO JEBP; BERTOLUCCI SKV. 2007. Comprimento da estaca e tipo de substrato na propagação vegetativa de atroveram. Ciência Rural 37: 1157-1160.

DUTRA LF; KERSTEN E; FACHINELLO JC. 2002. Época de coleta, ácido indolbutírico e triptofano no enraizamento de estacas de pessegueiro. Scientia Agricola, 59: 327-333.

EHLERT PAD; LUZ JMQ; INNECCO R. 2004. Propagação vegetativa da alfavaca-cravo utilizando diferentes tipos de estacas e substratos. Horticultura Brasileira 22: 10-13.

ESCOBAR P; LEAL SM; HERRERA LV; MARTINEZ MR; ATASHENKO E. 2010. Chemical composition and antiprotozoal activities of Colombian Lippia spp. essential oils and their major components. Memórias do Instituto Oswaldo Cruz 105: 184-190.

FIGUEIREDO LS; BONFIM FPG; FERRAZ EO; CASTRO CE; SOUZA MF; MARTINS ER. 2009. Influência do ácido indolbutírico no enraizamento de alecrim-pimenta (Lippia sidoides) em leito com umidade controlada. Revista Brasileira de Plantas Medicinais 11: 33-36.

FOCHESATO ML; SOUZA PVDS; SHAFER GS; MACIEL SH. 2008. Alterações das características químicas de três substratos comerciais na produção de mudas cítricas. Ciência e Agrotecnologia 32: 1040-1046.

FRANÇA SC. 2002. Abordagens biotecnológicas para a obtenção de substâncias ativas. In: SIMÕES CMO; SCHENKELEP; GOSMANN G; MELLO JCP; MENTZ LA; PETROVICK PR (eds). Farmacognosia: da planta ao medicamento. Porto Alegre/Florianópolis: Editora da UFRGS/Editora da UFSC. p.101122.

GOVAERTS R; ATKINS S. 2012, 07 de março. World Checklist of Verbenaceae. Facilitated by the Royal Botanic Gardens. Disponível em: <http://apps.kew.org/wcsp/synonomy. do? name_id=113656.

HERRERA-MORENO AM; CARRANZA CE; CHACÓN-SÁNCHEZ MI. 2013. Establishment of propagation methods for growing promising aromatic plant species of the Lippia (Verbenaceae) and Tagetes (Asteraceae) genera in Colombia. Agronomía Colombiana 31: 27-37.

LACERDA MRB; PASSOS MAA; RODRIGUES JJV; BARRETO LP. 2006. Características físicas e químicas de substratos à base de pó de coco e resíduo de sisal para produção de mudas de sabiá (Mimosa caesalpiniaefolia). Revista Árvore 30: 163-170.

MING LC; SILVA SMP; SILVA MAS; HIDALGO AF; MARCHESE JA; CHAVES FMC. 2003. Manejo e cultivo de plantas medicinais: algumas reflexões sobre perspectivas e necessidades no Brasil. In: COELHO MFB; COSTA JUNIOR P; DOMBROSKI JLD (orgs). Diversos olhares em Etnobiologia, Etnoecologia e Plantas Medicinais. Cuiabá: SBEE. 250p.

MORAIS SM. SILVAAKO; LIMA KSB; CUNHA NR; COSTA SMO; MENEZES JESA; MATOS FJA. 2008. Atividade sequestradora de radical livre, teor de compostos fenólicos e inibição da acetilcolinesterase de extratos de plantas medicinais das Farmácias Vivas. In: CONGRESSO BRASILEIRO DE QUÍMICA. Anais... Rio de Janeiro: ABQ. Disponível em: <http://www.abq.org.br/cbq/2008/ trabalhos/7/7-445-4813.htm>.

OLIVEIRA ACL; ARRIGONI-BLANK MF; BLANKAF; BIANCHINI FG. 2011. Produção de mudas de dois genótipos de alecrim-detabuleiro (Lippia gracilis) em função de fertilizante mineral, calcário, substratos e recipientes. Revista Brasileira de Plantas Medicinais 13: 35-42.

OLIVEIRA AF; PASQUAL M; CHALFUN NNJ; REGINA MA; RINCON CDR. 2003. Enraizamento de estacas semilenhosas de oliveira sob o efeito de diferentes épocas, substratos e concentrações de ácido indolbutírico. Ciência e Agrotecnologia 27: 117-25.

OLIVEIRA DR; LEITÃO GG; BIZZO HR; LOPES D; ALVIANO DS; ALVIANO CS; LEITÃO SG. 2007. Chemical and antimicrobial analyses of essential oil of Lippia origanoides. Food Chemistry 101: 236-240.

OLIVEIRA GL; FIGUEIREDO LS; MARTINS ER; COSTA CA. 2008. Enraizamento de estacas de Lippia sidoides utilizando diferentes tipos de estacas, substratos e concentrações do ácido indolbutírico. Revista Brasileira de Plantas Medicinais 10: 12-17.

PASCUAL ME; SLOWING K; CARRETERO E; SÁNCHEZ MATA D; VILLAR A. 2001. Lippia: traditional uses, chemistry and pharmacology: a review. Journal of Ethnopharmacology 76: 201-214.

PIMENTA MR; FERNANDES LS; PEREIRA UJ; GARCIA LS; LEAL SR; LEITÃO SG, SALIMENA FRG; VICCINI LF; PEIXOTO PHP. 2007. Floração, germinação e estaquia em espécies de Lippia L. (Verbenaceae). Revista Brasileira de Botânica 30: 211-220.

SALIMENA FRG. 2012. Verbenaceae. In: Lista de Espécies da Flora do Brasil. Rio de Janeiro: Jardim Botânico do Rio de Janeiro. Disponível em: (http://floradobrasil.jbrj.gov.br/2012/ FB021449).

SANTOS HS; COSTA SMO; PESSOA ODL; MORAES MO; PESSOA C; FORTIERB S; SILVEIRA ER; LEMOSA TLG. 2003. Cytotoxic naphthoquinones from roots of Lippia microphylla. Verlag der Zeitschrift für Naturforschung 58: 5117-5120.

WENDLING I. 2004. Propagação vegetativa de erva-mate (Ilex paraguariensis): estado da arte e tendências futuras. Colombo: Embrapa Florestas. 46p. 